\title{
Teaching Social Informatics for Engineering Students
}

\author{
László Z. Karvalics, Lilla Juhász \\ Dept. of Information and Knowledge Management, \\ Budapest University of Technology and Economics, Hungary \\ zkl@itm.bme.hu, juhasz.lilla@ittk.hu, http://www.itm.bme.hu/
}

\begin{abstract}
Courses on Social Informatics at the Budapest University of Technology and Economics have been offered since 1992. After 25 semesters, with more than 1200 students (mainly electrical engineering majors) who have taken the courses, our views on the subject, together with a comprehensive report on teaching experiences are now presented in a two volume handbook. We would like to share our notions on Social Informatics as a subject in its own right through an in-depth analysis of our curriculum philosophy and teaching methods.
\end{abstract}

Keywords: Social informatics, curriculum development, information as a cultural value. Ethics and IT, Budapest University of Technology and Economics

\section{Introduction}

On a professional meeting held in Budapest in December 2005 a young informatician having made a brilliant business career, recognizing one of the authors of this study, said to the audience: "And here sits my dear ex-teacher who prevented me from becoming a narrow-minded engineer, whose course titled 'Introduction into Social Informatics' rose my interest in continuously watching and interrogating the over-technology aspects."

The researcher and lecturer aim which led us to introduce our Social Informatics courses at the Technical University of Budapest in 1991 is better expressed by this quotation than by anything else. From the very beginning we set out from the opinion that in today's social theory it is 'information society studies' that gives the most comprehensive reflection of the challenges of this era, however, the technical intellectuals (primarily the informaticians) need to be able to connect the well-known informatics aspects and background knowledge to the relevant over-technology

Please use the following format when citing this chapter:

Karvalics, L. Z., Juhász, L., 2006, in IFIP Intemational Federation for Information Processing, Volume 223, Social Informatics: An Information Society for All? In Remembrance of Rob Kling, eds. Berleur, J., Numinen, M. I, Impagliazzo, J., (Boston: Springer), pp. 65-72. 
social aspects (Z. Karvalics - Székely, 1995, Z. Karvalics, 1998). In other words: the disadvantages emerging from the one-sided technical approach of informatician / engineer training must satisfactorily be counter-balanced. Consequently, the focus point of our attention has been permanently directed at scientific reflection to the current practical challenges.

This approach is slightly different from the mainstream standpoints (Kling, 1999, Sawyer - Rosenbaum, 2000, Ljubljana, 1985, Kling, 2001). The topics, subjects, our domains linking computer culture and the society are the same - we absolutely agree in what Social Informatics as a discipline is. The essential difference lies in what and how is represented in the university curriculum from this discipline, in the pedagogical targets we follow (Z. Karvalics, 2004).

So the basic target of our Social Informatics curriculum is to transmit, to impart a special approach in the possession of which the technical intellectuals (having the necessary technological knowledge) are open to the problems of the social subsystems, they have knowledge of its operation, they are able to evaluate empirical data and to make in-depth investigations of the main phases of information flow. We strive to give our students organized knowledge so that they will not be compelled to rely on resources dispersed here and there while getting to know the problems of social informatics.

The 'minimum' we have to perform is as follows:

- 'Building the non-shannonian conceptual net' related to information (introduction of the cultural, cognitive and economic-social concept network of information),

- Channeling the Perception,

- Building a new identity environment for the engineers,

- Mapping the topic.

\section{The Education Modules of Social Informatics}

\subsection{Problem Description}

In an informatics context we always speak of hybrid systems: a kind of system of human and signal processing machine(s). In this sense, the Internet is not 'a network of computers connected through communications lines' but a giant hybrid of people, content and complex informatics systems. Consequently, the performance and the possible system errors do not refer to the 'Computer' but to the human constructing, operating and maintaining it. Artificial intelligence does not 'conquer the human being' but helps him to achieve an operation performance exceeding his biological possibilities. On the other hand, we take information as a cultural value: in our opinion, information is nothing else but a special interaction through which a human being is able to establish and keep contacts with his environment. The six modules of our curriculum try to organize the course in line with this opinion. 


\subsection{The Phenomenon of Information}

We take the interpretation domain of 'information' exclusively as a part of the world of human phenomena, a kind of 'atom' of the ability of getting to know. Starting from the opinion that all information is (inter)action but not every (inter)action is information, we exclude the analogue moments of the material and living systems (genetic 'information', information as a 'physical' entity equal in value to scope, time and energy) from the discussion universe. The Shannon-Weaver transmission model is insufficient for the recognition of social interactions: the basic notions of the information universe are to be deduced from somewhere else. We found the source of our categories in cognitive psychology and the history of culture.

Table 1. Information and information technology

Meanings and fundamental concepts - theoretical introduction
Elementary information, information sets and supersets
Channels of elementary information
Information and action
Basic model of information flow
Informational activity forms and modes of objectivation
Information tools, information instruments, information technology

\subsection{Information and Knowledge Industry}

In the background of today's information technology industry and the developments we find the accelerating restructuring of the economic sectors, the transformation of reality almost impossible to be followed. Thus the second module surveys the questions of information and knowledge economy. In parallel with the sudden advance of the Internet and the 'network economy' the examination of 'e-economy' and 'new economy' has become to the foreground, and on the other hand, the categories of knowledge economy and knowledge-based economy have started to replace the use of information economy. Meanwhile, however, it is inevitable to give a summarizing and historical picture on the big blocks of computer industry, telecommunication and the media (content industry), in the terms of convergence.

Table 2. IT- Information- and Knowledge industry

World economy, international trade, business and information

Origins and Basics of Information and Knowledge Economy

Information Economy and Information Policy

Education

Research, Development and Innovation

The IT sector: clusters, dynamics, convergence

Internet-business, E-commerce 


\subsection{The 5 axioms of social informatics}

The third module presents the 5 axioms of social informatics through case studies and examples:

The human component is present in the hybrid systems triply: as 'producer' of the computer side, as 'user' or operator being in interaction with the computer, and as the one concerned by the results (outputs). The examination of the human factor is the deepest substance of the discipline. The most important Axiom of social informatics is: People first.

Table 3. How to think of ICT? The Five Axiom

\begin{tabular}{lll}
\hline $\begin{array}{l}\text { Standpoint } \\
\text { (Axiom) }\end{array}$ & Modality & $\begin{array}{l}\text { General } \\
\text { category }\end{array}$ \\
\hline World concept & $\begin{array}{l}\text { Approach } \\
\text { Culture }\end{array}$ & Embeddedness \\
PEOPLE & \multicolumn{2}{c}{ Substance } \\
FIRST & & \\
Community & Size & Evolution \\
Environment & System &
\end{tabular}

The hardware and software development of the hybrids is typically a collective performance. The human side of hybrid systems generally means 'a human connected into a network'. Each of the communication actions makes a community scope. Although the digital universe has problem sections that can be surveyed exclusively on an individual level, the examination of the characteristic contexts always need grouped or collective frameworks. (Axiom 2) The personal and community dimension of IT-universe is embraced by the 'culture' as the entity in the widest sense. (Axiom 3)

The persons and their communities possible to be described with certain cultural factors ask for the help of information technology in a certain environmental scope. Informal social environment, formal institutional environment, media environment and natural environment can be considered environmental elements. (Axiom 4). Finally, Axiom 5 is the entity that all the spectators and analysts approaching the ITworld must cross unperceived. Namely, the student, researcher, reporter, politician, or user interprets and analyzes the facts known properly or not by adjusting them to the models according to which they actually see the world. How do they look at the eternal questions of Life, Society or the World? What kind of samples do they mobilize in case they meet a problem?

The category of ethics becomes an essential category in the meeting-point of world concept and culture like this - it is not by chance that the first prototypes of social informatics taking up the form of university courses were the 'Ethics and IT' courses at the universities of the Francophone world at the beginning of the seventies. 
The modalities together constructing the general category of 'evolution' are size and the dynamics determining it in the case of community, and system view in the case of the environment. The more complexly we approach the macro-level questions of IT, the more our view is based on the evolutional approach ( $Z$. Karvalics, 2004).

\subsection{History as context}

The traditional fields of informatics must be given a new meaning embedded in a social scientific context. The aim is to adjust the history of technology into a sociohistorical framework, to get to know the applier culture, to investigate the processes going on in the deep layers of society and to survey the common factors forming the relationship between technology and society from the pre-historical phase up to this day.

Table 4. Pre-history of IT

\begin{tabular}{l} 
World economy, international trade, business and \\
information \\
\hline Social History of Computing \\
Conceptual and Social History of 'Network' \\
Social History of Internet \\
Social History of Data Storage and Processing \\
History of IT Industry \\
History of information sciences \\
History of IT-politics, IT-strategies
\end{tabular}

\subsection{Professions and Knowledges}

In the fifth module we examine the profession world of the information complex. As a result of the spread of the information technology tools and their becoming decisive factors on a social scale, as well, the knowledges necessary to execute information operations are moving more and more from the technical to the social or social scientific domain. This change, which has not yet been satisfactorily analyzed, also results in the re-thinking of the engineer knowledge worlds which we see possible to be presented in the activity matrix of social informatics. The matrix consists of the horizontal categories of researcher, engineer, technologist, broker and manager knowledges, their pre-history and trends and the vertical categories of $\mathrm{HW}$, $\mathrm{SW}$, system, information and knowledge. Filling up the abstract categories of the role players and knowledge types being present at the various points of IT, media, science and economy with real professions, brings about the recognition and understanding of several enlightening inter-connections. 
Table 5. Building an identity environment. Who are they?

\begin{tabular}{llllll}
\hline RESEARCHER & ENGINEER & $\begin{array}{l}\text { TECHNO- } \\
\text { LOGIST }\end{array}$ & BROKER & MANAGER & \\
\hline Knowledge & Knowledge & Knowledge & Knowledge & Knowledge & KNOWLEDG \\
researcher & engineer & technologist & broker & manager & E \\
Information & Information & Information & Information & Information & INFORMATI \\
researcher & engineer & technologist & broker & manager & ON \\
System researcher & System & System & System broker & System manager & SYSTEM \\
& engineer & technologist & & & \\
SW/HW researcher & SW/HW & SW/HW & SW/HW broker & SW/HW & SOFTWARE/ \\
& engineer & technologist & & manager & HARDWARE
\end{tabular}

\subsection{Problem Axes, Problem Maps}

Social theory has long been striving to define the sub-systems together making (constituting) Society as a whole. Since the great system builder, Talcott Parsons, several rival paradigms have tried to give the best systematization. Of the many possible models, the one standing nearest to us is that arranging the most important system categories of the life and survey of society into four-element groups (quads) exactly into four.

Table 6. The four quads

\begin{tabular}{lll}
\hline \multicolumn{1}{c}{ 'Name' } & Elements \\
\hline 1. quad & Basic Elements & Economy \\
& & Politics \\
& & Society \\
& Law \\
2. quad & Forms of mind and knowledge & Science \\
& & Art \\
& & Religion \\
& & Everyday Mind \\
3. quad Everyday life & The world of labour \\
& & Transport and environment \\
& & Health (care) \\
& & Leisure time \\
4. quad Basic Elements & Economy \\
& & Politics \\
& & Society
\end{tabular}

Let us imagine that the 4 quads form 16 problem axes each of them running into the ICT (Information and Communication Technologies) centre. The problems that can appear at all in a socio-informatics context are arranged on theses axes. 
And how does the axis become a problem map? The first step is the arrangement of all the possible issues evolving when the certain sub-system and the IT-universe meet. Depending on the 'saturation' of the axis, we can find 5-25 typical questions or problem fields which can be illustrated as meeting-points or 'nodes' on the axis. For example, economy is especially rich - it is not by chance that economy informatics is an independent knowledge world -, while the number of the elements of the node of religion and ICT is not very high (although very interesting).

We can speak of two types of nodes. Specific nodes indicate a problem being characteristic of only the certain sub-system, horizontal nodes are issues possible to study uniformly concerning each axis. These are, for example:

- the informatization process of an institution belonging to the certain subsystem

- the historic aspect: where does informatization process start from (with the involvement of the pre-digital information environment)

- the actual philosophical problems of the certain sub-system generated by the ICT

And since Reality does not care for socio-theoretical systematizations, some of the problems are not possible to be ordered to only one axis or to one of the nodes, but may refer to several nodes of several axes. Let us take, for example, the problem of 'intellectual property on the Internet': it is part of the Media sub-system as 'content', but the content itself is Art or Science. Regulation is a task of the Law subsystem, however, it is strongly influenced by Politics - while deep economic interrelations appear in the background. Consequently, the issues of social informatics are the various combinations of nodes in many cases. ( $Z$. Karvalics, 2004)

\section{Conclusion}

We are aware of the fact that the very same topics can be discussed in various pedagogical - didactical forms. Our education package has been developed for engineer students, with practical aims; still we believe that it will also contribute to the tracing of the disciplinary borderlines of social informatics. Of these aspects we highlight the historical dimension and the identity and professional environment which we consider as our own innovative contribution to the subject.

\section{References}

Kling, Rob (1999): What is Social Informatics and Why Does it Matter? D-Lib Magazine,

January 1999 Volume 5 Number 1. http:/www.slis.indiana.edu/SI/si2001.html

Kling, Rob (2001): Social Informatics. Encyclopedia of LIS, Kluwer

Ljubljana (1985): Social Informatics Web-site http://social-informatics.org/

Sawyer, Steve - Rosenbaum, Howard (2000): Social Informatics in the Information Sciences:

Current Activities and Emerging Directions Informing Science - Special Isssue on Information Science Research, Vol. 3. No. 2 (2000) pp. 89-95. 
Z. Karvalics, László (1998): Information Society and Social Informatics: Extended topology of the research fields/ In: Research for Information Society. Proceedings, Vol.II. Warsaw, 1998 October 15-17.

Z. Karvalics, László (2004): Designing a Discipline: Social Informatics Revisited. In: Jose V. Carrasquero et al. (eds): Informatics and Society, PISTA Proceedings Vol. I. IIS, 2004 pp. 317-321.

Z. Karvalics, László - Székely, Iván (1995): Informatics and informaticians: Changing concepts and a realized example of teaching and understanding informatics beyond computer technology In: Key players in the introduction of information technology: Their social responsibilities and professional training (Proceedings, Namur, July 5-7 1995) 237-244.o. 